\title{
Fabrication of Pure Copper Rod by Multi-beam Laser Metal Deposition with Blue Diode Lasers
}

\author{
Yuji Sato"1 ${ }^{*}$ Kazuhiro Ono ${ }^{2}$, Keisuke Takenaka², Kento Morimoto ${ }^{2}$, Yoshinori Funada ${ }^{3}$, Yorihiro Yamashita ${ }^{4}$, Tomomasa \\ $\mathrm{Ohkubo}^{5}$, Nobuyuki Abe², and Masahiro Tsukamoto \\ ${ }^{1}$ Joining and Welding Research Institute, Osaka University, Japan \\ ${ }^{2}$ Graduate School of Engineering, Osaka University, Japan \\ ${ }^{3}$ Industrial Research Institute of Ishikawa, Japan \\ ${ }^{4}$ National Institute of Technology, Ishikawa College, Japan \\ ${ }^{5}$ Dept. of Mechanical Engineering, Tokyo University of Technology, Japan \\ ${ }^{*}$ Corresponding author's e-mail: sato@jwri.osaka-u.ac.jp
}

\begin{abstract}
A three-dimensional rod of pure copper was fabricated by multi beam type laser metal deposition method with blue diode lasers. In order to clarify the mechanism of the 3D rod formation, the melting and solidification process during a rod formation was captured with a video camera. The pure copper rod with a length of $100 \mathrm{~mm}$ was successfully formed in 25 seconds at the power density for blue laser of $1.6 \times 10^{4} \mathrm{~W} / \mathrm{cm}^{2}$. In order to evaluate the rod shape, the cross-sectional area was measured. As the results, the long side of the formed pure copper rod was $780 \mu \mathrm{m}$ and the short side was 600 $\mu \mathrm{m}$, which was larger than the spot at the focal point. Furthermore, in order to evaluate the mechanical properties, tensile strength and hardness of the rod were measured. The rod had a maximum tensile strength of $229 \mathrm{~N} / \mathrm{mm}^{2}$ and an elongation rate of 30\%, which was low ductility. The fractured part was analyzed using a scanning electron microscope. As a result, it was found that the fracture surface of the rod was inhomogeneous with scattered holes.
\end{abstract}

DOI: $10.2961 /$ jlmn.2021.03.2007

Keywords: pure copper, multi-beam, laser metal deposition, additive manufacturing, rod formation

\section{Introduction}

Pure copper is widely used in many electric parts such as a solenoid due to having a high thermal conductivity and a high electrical conductivity. As electric cars become more prevalent, the market demand for welding, cladding, and cutting of copper is increasing. Although a thermal spray method and an electro-less deposition method are generally used to form a copper layer when adding different functions on a substrate, these methods have issues such as a low adhesive strength and a poor layer [1-3].

Recently, methods using a laser to form the copper layer have been reported. Mizoshiri et al. reported that copper thin films form from $\mathrm{CuO}$ nanoparticles in a reduction reaction with a femtosecond laser, but the purity of copper is low since $\mathrm{CuO}$ remains in the layer [4]. Mao et al. reported that the copper layer was deposited on the substrate by the chemical vapor deposition method with $\mathrm{CO}_{2}$ laser. It was difficult to form a thick layer over $1 \mu \mathrm{m}$ [5]. In plasma transfer arc welding (PTA), copper or copper alloy thin films is possible to be formed on the metal substrate, since a plasma arc is used as a heat source. However, the plasma arc is difficult to control the heat input, and excessive heat input causes dilution of the substrate material into the layer $[6,7]$. Molleda et al. reported a furnace brazing process coated copper on carbon steel [8]. In their method, the original characteristics of the materials such as $\mathrm{Cu}$ and carbon steel are not exhibited because the sample depends on the blazing material.

Our research has focused on a laser metal deposition (LMD) method, which can form a dense and highly metal layer since a laser can directly melt and solidify the coating material. The LMD method, which is a laser additive manufacturing technology, is attractive due to its ability to freely form shapes. Additionally, it is an effective metal surface cladding technique capable of increasing component lifetimes when an additive material such as a powder or a wire is melted by a laser and deposited on the substrate [912]. Compared with other methods (e.g., PTA, thermal spray, etc.), the advantages of LMD are a small heat-affected zone, a low heat distortion of the substrate, and a high adhesion strength to the substrate.

LMD uses, generally, lasers in the near infrared region such as a direct diode laser, a disc laser, a fiber laser. However, pure copper layer formation is challenging due to its low light absorption at these wavelengths. At the wavelength of $1 \mu \mathrm{m}$, the absorption rate for copper is recorded to only $6 \%$. The light absorption rate of copper depends on the wavelength, the light absorption rate increases as the wavelength become shorter [13]. Himani et al. demonstrated that the copper was formed on the substrate with high power green laser [14]. The light absorption rate at a 450 -nm wavelength increases to $60 \%$. In response, we have employed a blue direct diode laser at a $450-\mathrm{nm}$ wavelength for LMD and developed a blue direct diode laser induced LMD system [B-LMD]. Our B-LMD is employed multi beam type LMD system using two lasers to supply a cladding powder from the center nozzle, realizing a low dilution area and micro cladding [15-20]. In this study, we demonstrate that a 3D rod of pure copper layer is formed on plate by $\mathrm{B}-\mathrm{LMD}$. Additionally, the cladding process is evaluated 
in real time with a video camera and investigated the mechanical property of 3D rod.

\section{Experimental procedure \\ 2.1 Powder}

A pure copper powder, which was prepared via a premixed atomization process from Sanyo Spatial Steel co., was used in this study. The copper powder having a purity of $99.99 \%$ was produced by a gas atomized method. The powder size was measured with a particle size distribution analyzer. The powder had a spherical shape with a particle size around $35 \mu \mathrm{m}$ and standard deviation of $12 \mu \mathrm{m}$ as shown in Fig.1.

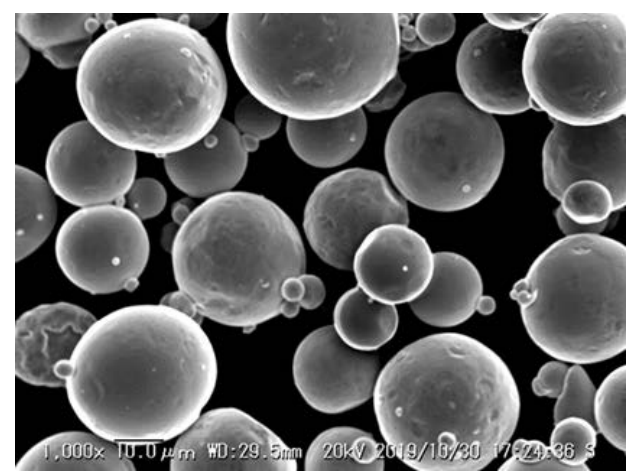

Fig.1 SEM image of pure copper powder.

\subsection{Experimental procedure for 3D rod formation with B-LMD}

Figure 2 (a) shows the schematic diagram of experimental setup for a pure copper rod formation with B-LMD $[18,19]$. Two diode laser modules were employed. The output power and wavelength for the one module were $100 \mathrm{~W}$ and $450 \mathrm{~nm}$, respectively. The two lasers were guided to the focusing head with optical fibers. Each fiber had a core diameter of $200 \mu \mathrm{m}$. The beam profile at the focal point of the combined two lasers was set to a spot diameter of 590 $\mu \mathrm{m}$ in the $\mathrm{x}$ axis direction and $530 \mu \mathrm{m}$ in the $\mathrm{y}$ axis direction at full width at half maximum by a CCD camera (Fig. 2 (b)). The processing head supplied the powder at a focal point from a center nozzle. A stainless steel-type 304 substrate with a $1.0-\mathrm{mm}$ thickness was used. When laser irradiation and powder feeding were simultaneously performed toward to the substrate, the powder melted and solidified on the substrate to form a pure copper layer and then processing head was going up vertically to form a $3 \mathrm{D}$ rod. The laser power density was set at from $1.6 \times 10^{4} \mathrm{~W} / \mathrm{cm}^{2}$. The powder feed rate was kept constant at $37 \mathrm{mg} / \mathrm{s}$, and Ar gas was flowed at a rate of $10 \mathrm{~L} / \mathrm{min}$ as a shield gas to prevent oxidation.

\subsection{Evaluation of mechanical properties for 3D rod.}

In order to evaluate the rod formation process, the video camera was set and recorded an illuminated image with a halogen light via a band pass filter at the horizontal direction in real time. After rod formation, the cross-sectional area was investigated with an optical micro-scope (OM) to measure the crystal grain of cross-sectional surface corroded with ammonium hydrogen peroxide solution. 4 points of the Vickers hardness (HV) were measured on the cross sectional area of the pure copper rod to obtain the average value with micro Vickers Hardness tester before corrosion. Moreover, tensile test was done by using the tensile tester (Autograph AGS-X, Shimazu co.) at a constant crosshead speed of $2 \mathrm{~N} / \mathrm{mm}^{2} / \mathrm{s}$, up to the final failure of the joint in order to measure ultimate tensile strength (UTS). Since the diameter of the test piece was $1 \mathrm{~mm}$ or less, the grip interval and test speed were set to $50 \mathrm{~mm}$ and $2 \mathrm{~N} / \mathrm{mm}^{2} / \mathrm{s}$, respectively. After tensile test, the fracture surface was observed using a scanning microscope (SEM) and OM. To compare with a $\varphi 1.2 \mathrm{~mm}$ tough pitch wire, similar measurements were performed.

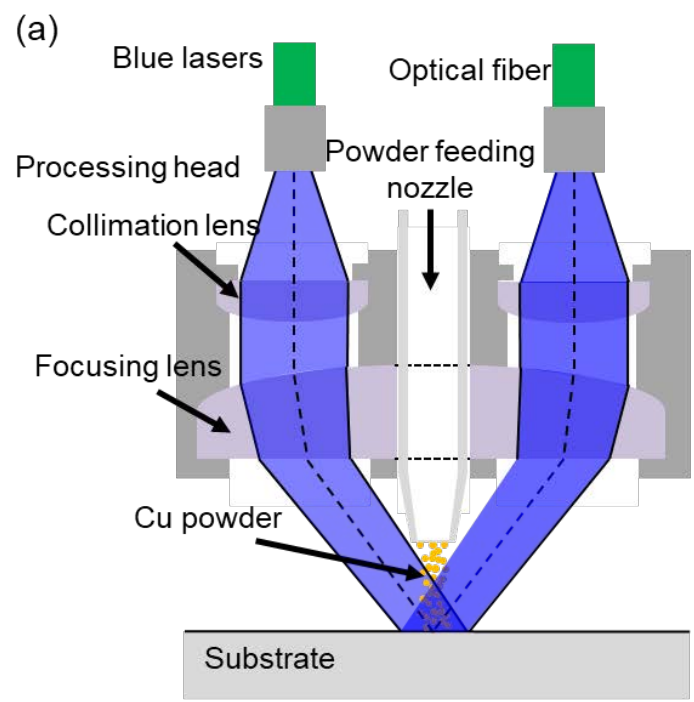

(b)

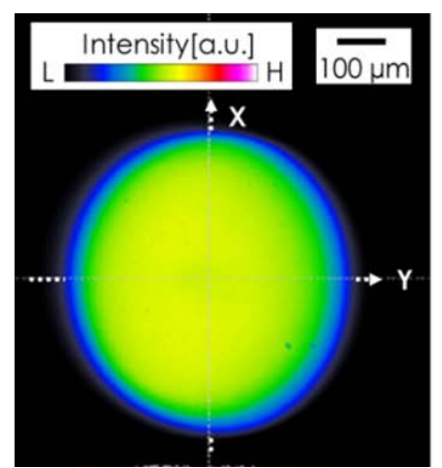

Fig.2 (a) Schematic diagram of B-LMD for rod formation and (b) beam profile on the processing point.

\section{Results and Discussion \\ 3.1 3D rod formation by B-LMD}

Figure 3 shows the rod formation process captured with a video camera. When the powder feeding and the laser irradiation were simultaneously performed to the substrate, the powder was melted to form a molten layer and then solidified on the substrate to form a copper thin layer. To repeat this process, the pure copper rod with $100 \mathrm{~mm}$ was formed in $25 \mathrm{~s}$ at the laser power density of $1.6 \times 10^{4} \mathrm{~W} / \mathrm{cm}^{2}$, the powder feed rate of $37 \mathrm{mg} / \mathrm{s}$ and the processing head sweep speed of $4 \mathrm{~mm} / \mathrm{s}$, as shown in Fig.3 (e). The thickness of the rods was measured at five points every $20 \mathrm{~mm}$ from the starting point of modeling. As a result, the thicknesses at $10 \mathrm{~mm}, 30 \mathrm{~mm}, 50 \mathrm{~mm}, 70 \mathrm{~mm}$, and $90 \mathrm{~mm}$ from the starting point were $723 \mu \mathrm{m}, 757 \mu \mathrm{m}, 728 \mu \mathrm{m}, 738 \mu \mathrm{m}$, 
and $723 \mathrm{~mm}$, respectively, and the overall difference in thickness variation was within 5\%.

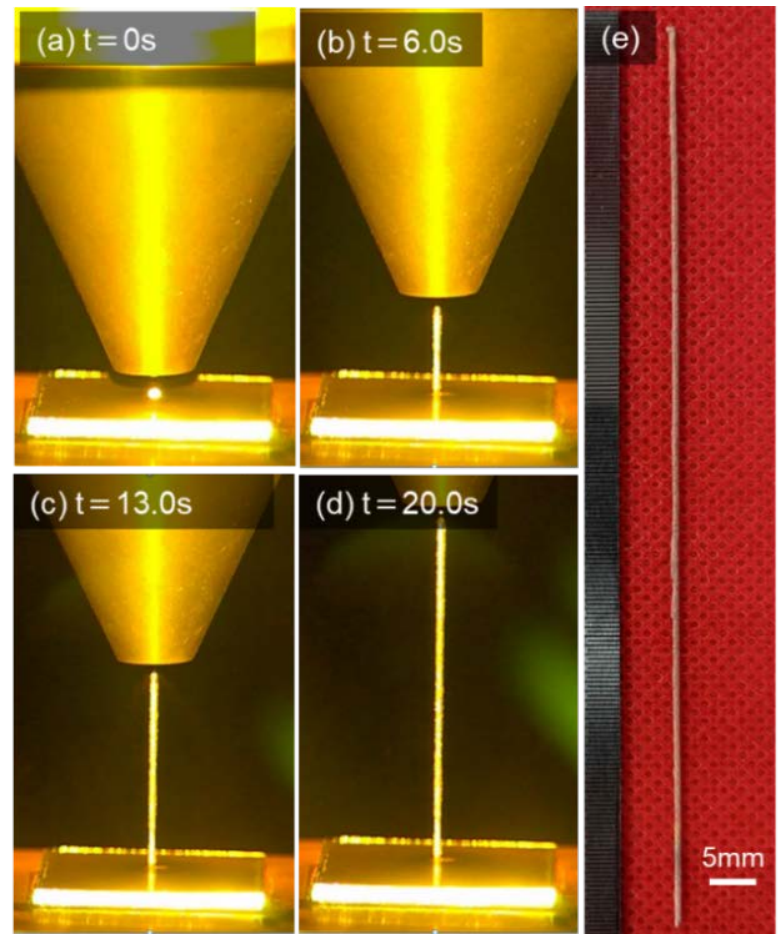

Fig.3 Video camera images of rod formation at (a) $t=0 \mathrm{~s}$, (b) $t=6 s$, (c)t=13.0s and (d) $t=20.0 s$, and (e) is a photo image of $3 \mathrm{D}$ rod formation

\subsection{Evaluation of cross-sectional area}

Figure 4 displays the OM image of cross-sectional surface of pure copper rod at the laser power density of $1.6 \times 10^{4} \mathrm{~W} / \mathrm{cm}^{2}$. The rod was cut perpendicular to the growth direction, and after filling with resin, polishing and etching, the cross section was observed using the OM. A dense layer and few voids were observed. It was founded that the pure copper rod had a long side of $780 \mu \mathrm{m}$ and short side of $600 \mu \mathrm{m}$ and was larger than the laser spot. Since the rod is irradiated with the laser defocused, the irradiated area is wider than focal point. When the laser profile at $\mathrm{Z}=300$ $\mu \mathrm{m}$ and the cross section of the pure copper rod were overlapped, the diameter of the pure copper rod coincided with the laser irradiation as shown in Fig.5. This is considered to be the result of two phenomena in multi-beam LMD, one is that the feed powder is heated by the laser and melts to form a rod when it reaches the rod tip, and the other is that the unmelted powder is trapped in the molten layer and melts by thermal conduction. This is due to the fact that some of the unmelted powder is trapped in the molten layer and melted by thermal conduction. At a laser power density of $1.6 \times 10^{4} \mathrm{~W} / \mathrm{cm}^{2}$, powders with a particle size of $15 \mu \mathrm{m}$ or less can be melted in flight [19], however powders with a larger particle size are trapped in the molten layer in an unmelted state. After trapping, they are additionally heated by the laser to melt, which increases the volume. In this experiment, powder was used with an average particle size of 35 $\mu \mathrm{m}$ as shown in Fig.1, resulted in about 1/3 of the powders are trapped in molten layer in an unmelted state, and the rods are considered to form at $\mathrm{Z}=300 \mu \mathrm{m}$ position.
It was found that the cross-sectional shape of pure copper rod was determined by the position irradiated by the laser. It was expected that the cross-sectional shape of the pure copper rod could be controlled by changing the method of laser irradiation. Moreover, Vickers micro hardness of the rod were measured before the corrosion. The hardness of the commercial pure copper was $54 \mathrm{HV}$. The Vickers micro hardness of the rod was obtained to $65 \pm 15 \mathrm{HV}$ higher than commercial pure copper. After corrosion with ammonium hydrogen peroxide solution, the grain size was measured by the OM. From Fig.4, fine grain was appeared. The hardness of the fabricated samples was improved owing to the laser heating rapidly of each layer caused by the rapid melt and solidification of the material. According to the reference [20], it reported that the grain size on the fabricated commercial pure copper by LMD processing was became larger to depend on the laser scanning speed. The size of crystal grain is attributed to the cooling rate after laser irradiation. According to reference [21], grain size of weld bead for pure copper by laser irradiation became large as the laser sweep speed decreased. This indicates that the pure copper grains are strongly dependent on the laser input energy. Therefore, the fine grains of our rod show the same tendency as the weld bead with less heat input.

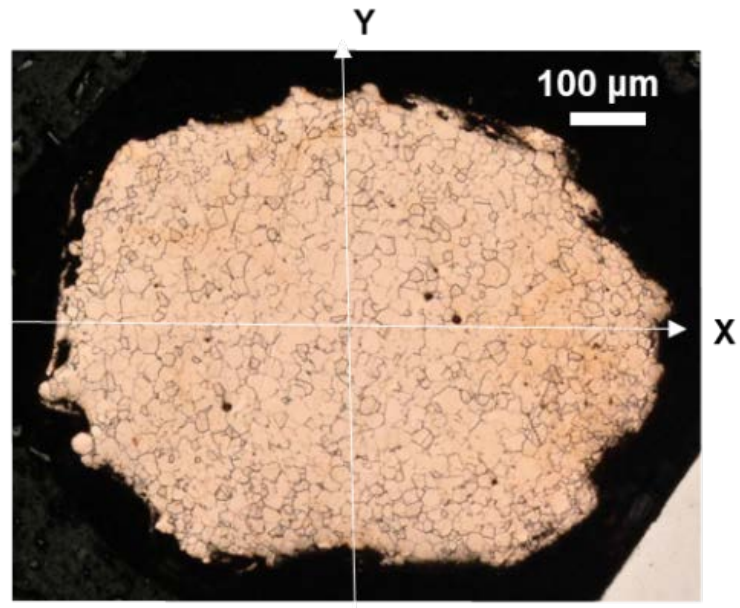

Fig.4 OM image of cross-sectional surface of 3D rod corroded with ammonium hydrogen peroxide solution.

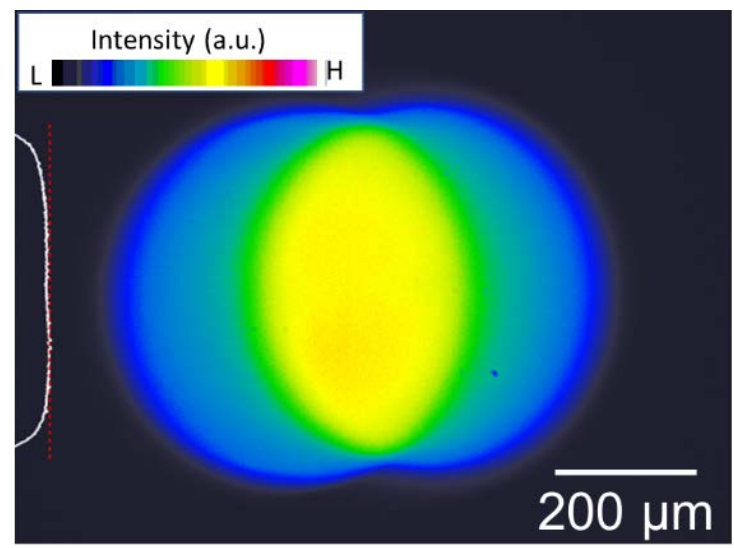

Fig.5 Beam profile of blue laser at focal position of the $\mathrm{Z}=300 \mu \mathrm{m}$

\subsection{Investigation of mechanical property}


Figure 6 shows the results of tensile strength measurement for the pure copper rod compared with $\varphi 1.2 \mathrm{~mm}$ tough pitch copper wire. The maximum tensile strength of $\varphi 1.2$ $\mathrm{mm}$ tough pitch copper wire was $243 \mathrm{~N} / \mathrm{mm}^{2}$ and the elongation rate was $42 \%$, but the rod had a maximum tensile strength of $229 \mathrm{~N} / \mathrm{mm}^{2}$ and an elongation rate of $30 \%$, which was low ductility. The fractured part was analyzed using OM and SEM. As a result, it was found that in tough pitch copper, fine voids were formed uniformly in the cross section. On the other hand, the fracture surface of the rod was inhomogeneous with scattered holes. It is considered that this is due to the fact that a slight void was formed in the rod formed by the B-LMD process as shown in Fig. 4, and that the starting point was the fracture. It is considered that this is because a slight void was formed in the rod formed by the B-LMD process as shown in Fig. 7, which was the starting point and caused the fracture. Furthermore, from Fig. 7 (d) and (f), it is seemed that some non-melted powder remained at the fracture surface of the rod. It can be assumed that a part of the rod was joined as a powder sintered and broke at the sintered position having a low bonding force. Therefore, it is considered that the rod is inferior in the tensile strength of commercially pure copper.

The pure copper rods were formed by the multi beam type LMD using blue diode lasers, and $100 \mathrm{~mm}$ pure copper rod was formed in 25 seconds. As a results of measuring the cross-sectional shape of the rod, it was found that the cross sectional shape of the rod depended on the beam diameter of the processing point. Furthermore, although the ductility of the rod was inferior to that of commercially copper wire, this result suggests that it is possible to form any shape of pure copper from powder, which will increase the design possibility of the pure copper products and contribute to the development of high-performance copper products.

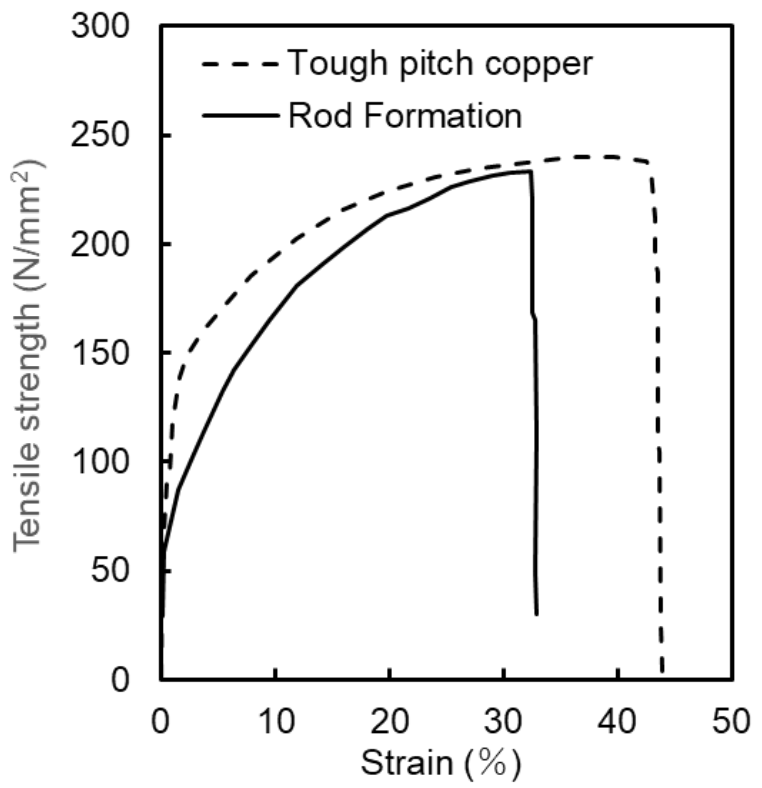

Fig.6 Correlation between the strain and tensile strength due to compare with the tough pitch copper and the rod fabricated by B-LMD
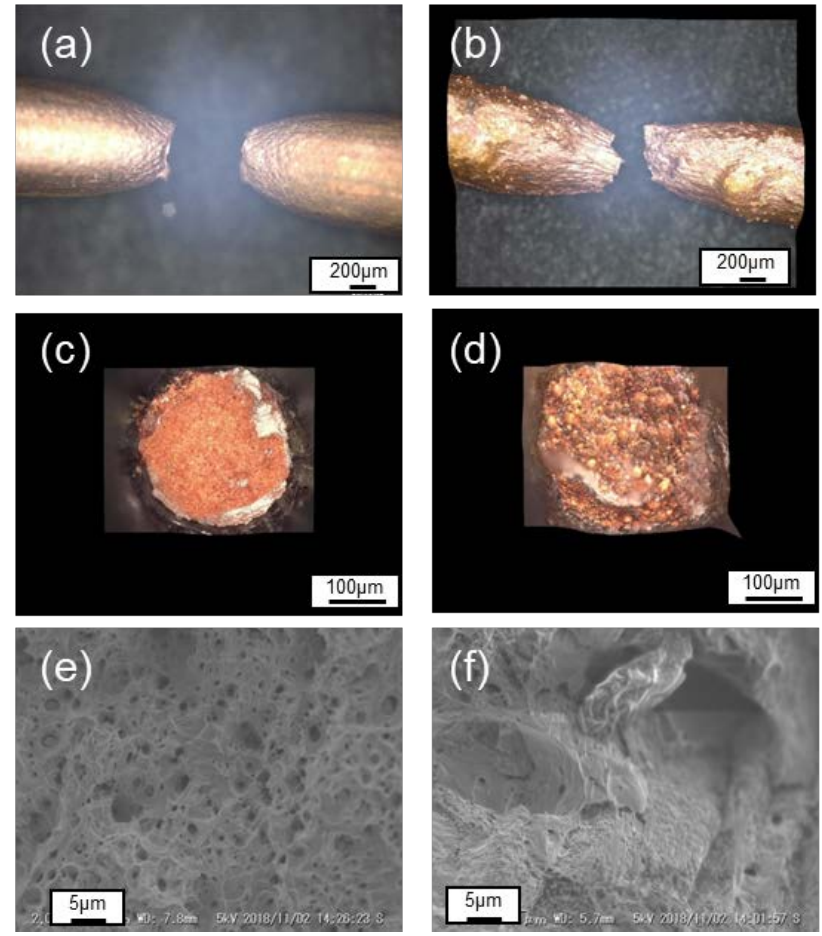

Fig.7 Fracture surface in (a), (c), (e) tough pitch commercial copper wire and in (b), (d), (f) the rod fabricated by B-LMD. (a) and (b) show photo of ductile destruction, (c) and (d) are OM images of cross section, and (e) and (f) are SEM images in the (c) and (d), respectively.

\section{Summary}

The 3D rod of pure copper was fabricated from powder by B-LMD. In order to evaluate the rod shape, the crosssectional area was measured. As the results, the long side of the formed pure copper rod was $780 \mu \mathrm{m}$ and the short side was $600 \mu \mathrm{m}$, which was larger than the spot at the focal point. Furthermore, in order to evaluate the mechanical properties, tensile strength and hardness of the rod were measured. The rod had a maximum tensile strength of 229 $\mathrm{N} / \mathrm{mm}^{2}$ and an elongation rate of $30 \%$, which was low ductility. The fractured part was analyzed using a scanning electron microscope. As a result, it was found that the fracture surface of the rod was inhomogeneous with scattered holes.

\section{Acknowledgement}

This research is partly supported by Adaptable and Seamless Technology transfer Program through Target-driven R\&D (A-STEP) from Japan Science and Technology Agency (JST) Grant Number JPMJTM20QF.

\section{References}

[1] F. Gärtner, T. Stoltenhoff, T. Schmidt, and H. Kreye: J. Therm. Spray Technol., 15, (2006) 223.

[2] A. Sova, S. Klinkov, V. Kosarev, N. Ryashin, and I. Smurov: Surf. Coat. Technol., 220, (2013) 98.

[3] O. Sharifahmadian, H.R. Salimijazi, M.H.Fathi, J. Mostaghimi, and L. Pershin: Surf. Coat. Technol., 233, (2013) 74.

[4] M. Mizoshiri, S. Arakane, J. Sakurai, and S. Hata: Appl. Phys. Express, 9, (2016) 036701. 
[5] D. M. Mao, Z. K. Jin, and Q. Z. Qin: J. Appl. Phys., 71, (1992) 6111.

[6] Wei Dai, Yafeng Miao Jianjun Li, Zhizhen Zhen, Dawen Zeng, and Qiwen Huang: J. Alloys Compd., 689, (2016) 680.

[7] Q. Y. Hou, T. T. Ding, Z. Y. Huang, P. Wang, L. M. Luo, and Y. C. Wu: Surf. Coat. Technol., 283, (2015) 184.

[8] F. Molleda, J. Mora, J.R. Molleda, E. Carrillo, E. Mora, and B.G. Mellor: Mater. Charact., 59, (2008) 613.

[9] K. Zhang, S. Wang, W. Liu, and R. Long: Appl. Surf. Sci., 317, (2014) 839.

[10] G. Xu, M. Kutsuna, Z. Liu, and K. Yamada: Surf. Coat. Technol., 201, (2006) 1138.

[11]F. Luo, J. Yao, X. Hu, and G. Chai: J. Iron Steel Res. Int., 18, (2011) 73.

[12] J. M. Pelletier, F. Oucherif, P. Sallamand, and A. B. Vannes: J. Mater. Sci., 202, (1995) 142.

[13] K. Asano, M. Tsukamoto, Y. Sechi, Y. Sato, S. Masuno, R. Higashino, T. Hara, M. Sengoku, and M. Yoshida: Opt. Laser Technol., 107, (2018) 291.

[14]H. S. Prasad1, F. Brueckner, J. Volpp, and A. F. H. Kaplan: J. Adv. Manuf. Technol., 107, (2020) 1559.
[15] K. Asano, M. Tsukamoto, Y. Funada, Y. Sakon, N. Abe, Y. Sato, R. Higashino, M. Sengoku, and M. Yoshida: J. Laser Appl., 30, (2018) 032602.

[16] Y. Sato, M. Tsukamoto, T. Shobu, Y. Funada, Y. Yamashita, Y. Sakon, and N. Abe, J. Jpn. Laser Process. Soc., 25, (2018) 12. (in Japanese)

[17] Y. Sato, M. Tsukamoto, T. Shobu, R. Higashino, Y. Funada, Y. Yamashita, Y. Sakon, and N. Abe: Proc. SPIE, Vol. 10523, (2018) 105230M.

[18] Y. Sato, M. Tsukamoto, T. Shobu, Y. Yamashita, T. Hara, M. Sengoku, Y. Sakon, T. Ohkubo, M. Yoshida, and N. Abe: Appl. Surf. Sci., 480, (2019) 861.

[19] T. Hara, Y. Sato, R. Higashino, Y. Funada, T. Ohkubo, K. Morimoto, N. Abe, and M. Tsukamoto: Appl. Phys. A, 126, (2020) 418.

[20] K. Ono, Y. Sato, R. Higashino, Y. Funada, N. Abe, and M. Tsukamoto: J. Laser Appl., 33, (2021) 012013.

[21] N. Eisenreich, M. Aeckerle, C Bantel, A. Heider, and A. Olowinsky: J. Laser Appl., 31 (2019) 022411.

[22] H. A. Baida, C. Langlade, G. Kermouche, and R. R. Ambriz, J. Mater. Res., 30, (2015) 2222.

(Received: June 30, 2021, Accepted: December 25, 2021) 